\title{
Which stream wood becomes functional following wildfires?
}

\author{
Pedro G. Vaz ${ }^{\mathrm{a}, *}$, Eric C. Merten ${ }^{\mathrm{b}}$, Dana R. Warren ${ }^{\mathrm{c}}$, Christopher T. Robinson ${ }^{\mathrm{d}, \mathrm{e}}$, \\ Paulo Pinto ${ }^{\mathrm{f}}$, Francisco C. Rego ${ }^{\mathrm{a}}$ \\ a Centre of Applied Ecology “Prof. Baeta Neves”, Institute of Agronomy, Technical University of Lisbon, Tapada da Ajuda, 1349-017 Lisbon, Portugal \\ ${ }^{b}$ Department of Biology, Wartburg College, Waverly, IA 50677, United States \\ ${ }^{\mathrm{c}}$ Department of Fisheries and Wildlife, Oregon State University, Corvallis, OR 97331, United States \\ ${ }^{\mathrm{d}}$ Department of Aquatic Ecology, Eawag, 8600 Duebendorf, Switzerland \\ ${ }^{\mathrm{e}}$ Institute of Integrative Biology, ETH-Zürich, Zürich, Switzerland \\ ${ }^{\mathrm{f}}$ Water Laboratory, Centre for Geophysics of Évora, University of Évora, Largo dos Colegiais, 7001 Évora codex, Portugal
}

\section{A R T I C L E I N F O}

\section{Article history:}

Received 1 August 2012

Received in revised form 10 January 2013

Accepted 16 January 2013

Available online 26 February 2013

\section{Keywords:}

Emulating natural processes

Euro-Mediterranean

Fire

Function

Large wood

Stream restoration

\begin{abstract}
A B S T R A C T
Large wood is a critical element in stream ecosystems, but only a subset of wood pieces actually provide hydraulic, geomorphic, and ecological functions. We test the current paradigm that larger pieces provide more function, and examine the role wildfires may play in affecting functionality of recruited wood. We conducted a cross-basin analysis in nine central Portugal watersheds, obtaining a variety of measurements on 1483 wood pieces (diameter $\geq 0.05 \mathrm{~m}$; length $\geq 0.5 \mathrm{~m}$ ) in 27 streams burned within six years prior. We examined nonlinear relationships and indirect effects on function using Generalized Additive Modeling and Structural Equation Modeling. Variables with direct effects on function were piece diameter, rootwads, anchoring, position (bridging, ramping, loose), longitudinal distance along the stream continuum, and the ratio of piece length to channel width. The effect of length ratio on function was nonlinear. Relatively long pieces were more likely to be functional until they were $\sim 3$ times the channel width, at which point longer pieces became less likely to be functional. Post-fire wood likely lacked complexity and longer pieces were more likely to be bridging; both conditions may have prohibited them from interacting with the wetted area. Wildfires had indirect effects on function. Burned pieces were more likely to be large in diameter (thus more likely functional) but not anchored (thus less likely functional); these antagonistic effects may be the reason burned status had no direct effect on function. Our results challenge the wellestablished idea that the function of wood in streams is simply a matter of wood size, along with indicators of longevity (e.g. stability and decay status). Relatively long pieces may in fact provide less function to the stream, at least until they break or are transported further downstream. Practitioners installing wood to streams should consider pieces with wide diameter and rootwads, approximately 3 times the channel width, and anchored but not bridging the channel.
\end{abstract}

(c) 2013 Elsevier B.V. All rights reserved.

\section{Introduction}

Large wood is widely recognized as an important structural element in stream ecosystems, but only a subset of wood pieces actually influence stream hydraulics, channel morphology, sediment and organic matter retention, flow routing and storage, habitat heterogeneity, and biological communities (Gregory et al., 2003 and references therein). We refer to such pieces as functional; that is, performing some observable function in the stream. Major

\footnotetext{
* Corresponding author. Tel.: +351 213653333; fax: +351213623493. E-mail addresses: pjgvaz@isa.utl.pt, zasvaz@gmail.com (P.G. Vaz), eric.merten@wartburg.edu (E.C. Merten), dana.warren@oregonstate.edu (D.R. Warren), robinson@eawag.ch (C.T. Robinson), ppinto@uevora.pt (P. Pinto), frego@isa.utl.pt (F.C. Rego).
}

knowledge gaps remain regarding the recruitment of functional large wood, including the influence of disturbance history such as riparian fires (Nakamura and Swanson, 2003). In this study, we evaluated which wood pieces have a high probability of becoming functional in streams following wildfire.

Broadly, the fact that fire affects stream wood input has been well documented and is apparent in the stock of burned wood in streams following a fire (Zelt and Wohl, 2004). In addition to the direct effects on tree mortality and associated wood recruitment, fire may also promote wood recruitment indirectly by increasing the susceptibility of riparian trees to windthrow and disease (Benda et al., 2003). Wood affects stream features, redirects flow, and traps other wood moving through the system only if it remains stable and is of sufficient size and shape (Abbe et al., 2003). Quantification of functional wood is rare and the effects of wildfire on stream wood function (rather than overall stock) remain largely unexplored. 
Over the past several decades, various studies have identified functional roles of stream wood (SW), but only a few characterized the functional wood itself. Most studies have focused on the relationship between SW quantity and channel structure (Thompson, 1995; Manga and Kirchner, 2000; Chen et al., 2008). However, the characteristics of individual pieces can also affect SW function in small streams (Rosenfeld and Huato, 2003). Studies on SW function have separately focused on particular categories: geomorphological, ecological, and hydraulic function. However, it is difficult to isolate such functions, since a single piece of wood can cover all three categories. Cordova et al. (2007), for example, documented up to five functions for one piece of SW. Rather than splitting SW functions into specific sub-categories in the current study, we consider any piece of wood having at least one function recognized in the literature and directly observed in the field to be functional (Montgomery et al., 2003).

Determining stream wood function requires knowledge of both the quantity and "quality" of individual pieces. SW quality depends on critical functional factors such as its physical structure (Vaz et al., 2011), its local position relative to the stream channel, its interaction with other wood, its distance along the stream, and its location throughout the river network (Martin and Benda, 2001; Jones et al., 2011). Among the structural characteristics of SW, there is a set of core variables that interact with the stream to influence wood function (Gregory et al., 2003; Bocchiola et al., 2006; Wohl et al., 2010). Major structural factors that may influence SW function are piece diameter, presence of rootwads and branches, decay state, form, and piece species. Elements of the SW relationship with a stream channel include wood length/channel width ratio, how it rests within the channel (position), degree of anchoring, and horizontal orientation (Braudrick and Grant, 2000; Chen et al., 2008; Cordova et al., 2007; Baillie et al., 2008; Magilligan et al., 2008; Jones et al., 2011). In an earlier study, we documented that burned wood recruited to streams following a fire generally was thicker, had less structural complexity, and was more decayed than wood that was not burned (Vaz et al., 2011). This suggested that SW burned status, while affecting size, geometry, and overall stability, will also likely influence the effect of SW on stream physical processes. In the current study, we incorporated SW burned status with a large suite of potential functional factors and evaluated how they interact to influence stream function.

A few studies have examined relationships between observable functions of a particular category and SW characteristics. For example, probability of pool habitat formation increases with SW diameter and presence of rootwads (Braudrick and Grant, 2000, 2001; Magilligan et al., 2008), and Beechie and Sibley (1997) identified a minimum-diameter threshold below which SW is unlikely to initiate pool formation. In addition, decayed SW contributes more to bank stability, sediment retention, debris jams, and riffle and pool formation (Jones et al., 2011). Abbe and Montgomery (2003) found that wood longer than half the bankfull width could initiate logjams. Only one study (Rosenfeld and Huato, 2003), specifically evaluated the probability of individual SW pieces becoming functional, although the dataset did not capture functions beyond the creation of primary pools.

In this study, we propose an initial framework for using SW critical factors (regarding physical structure and relation to the stream channel) to assess its functionality in streams following wildfire. We conducted a cross-basin analysis in nine central Portugal watersheds, obtaining a variety of measurements on 1483 individual SW pieces in 27 streams burned within six years prior. Large SW amounts within these streams are remarkably low (3.3 pieces per $100 \mathrm{~m}$ ), and so functional wood acquires additional importance (Vaz et al., 2011, 2013). This work encompassed a range of stream sizes and upland land-uses, including three common fire-prone forest types in southern Europe. We addressed the following objectives and associated hypotheses:

(1) Determine SW critical functional predictors and quantify their influence on the probability of stream function following wildfires. Hypothesis: As we had a broad criteria capturing observable SW functions, we expect that major SW critical factors (such as diameter, presence of rootwads or branches, decay state, degree of anchoring, and piece length/channel width ratio) will significantly influence the probability of a given piece being functional following wildfires.

(2) Determine how SW critical functional predictors and burned status interact to influence stream function. Hypothesis: As burned status influences SW size positively and complexity negatively (Vaz et al., 2011), we expect no clear direct relationship between SW burned status and function. Instead, we hypothesize that burned status will likely affect stream function indirectly through relationships with SW critical functional predictors.

This knowledge is essential for assisting resource managers in maximizing the effectiveness of riparian management (e.g. selective harvest, thinning) and stream wood installation to mimic natural processes and restore ecological functions.

\section{Materials and methods}

\subsection{Study area and site selection}

We conducted this study in east-central Portugal $\left(39^{\circ} 16^{\prime}\right.$ to $39^{\circ} 39^{\prime} \mathrm{N}, 7^{\circ} 30^{\prime}$ to $8^{\circ} 14^{\prime} \mathrm{W}$ ) from October 2009 to August 2011 in nine sub-basins of the Tagus River, which experienced extensive wildfires between 2003 and 2007. The area has gentle relief with altitudes ranging from 19 to $643 \mathrm{~m}$ (mean $\sim 266 \mathrm{~m}$ ). The land cover is dominated by forests, shrublands, and agriculture. The local climate is Mediterranean with hot, dry summers and cool, wet winters. Mean annual precipitation is $512 \mathrm{~mm}$ (range: $3 \mathrm{~mm}$ in July to $82 \mathrm{~mm}$ in November) and mean annual temperature is $15.8^{\circ} \mathrm{C}$ (range: $9{ }^{\circ} \mathrm{C}$ in December-January to $23^{\circ} \mathrm{C}$ in July-August). The selected burned sub-basins (mean drainage area $59 \mathrm{~km}^{2}$; range: $26-143 \mathrm{~km}^{2}$ ) represented three dominant forests in Portugal eucalyptus (Eucalyptus globulus), maritime pine (Pinus pinaster), and cork oak (Quercus suber). Within each sub-basin, three homogeneous reaches ( $\sim 500 \mathrm{~m}$ each) having a burned sideband of at least $100 \mathrm{~m}$ were selected, one each from stream order 1-3 (Strahler, 1957). We selected reaches distributed as evenly as possible from stream sources to mouths across the 27 streams. In total, 27 burned reaches were assessed, totaling $\sim 13,460 \mathrm{~m}$ of stream channel. Many of the streams were intermittent, with stretches remaining dry for several months, in a seasonal sequence of flooding and drought events.

Riparian zones (with a distinct riparian community) along streams in maritime pine and eucalyptus forests were often present (0-15 $\mathrm{m}$ in width) but cork oak sub-basins generally had more limited riparian zones. The uncultivated riparian vegetation was dominated by ash (Fraxinus angustifolia), alder (Alnus glatinosa), black poplar (Populus nigra), and willow (Salix atrocinerea, S. alba, S. salvifolia), frequently surrounded by edges of bramble-thicket (Rubus ulmifolius). In most southern areas, hawthorn (Crataegus monogyna) was also common. In addition to the indigenous species, silver wattle (Acacia dealbata), an exotic invasive and fire-prone tree, was widespread across the surveyed riparian zones (Silva et al., 2011). Further details about the study area are provided in Vaz et al. (2011). 


\subsection{Data collection}

Each study site included one representative $500 \mathrm{~m}$ reach where we measured dead downed wood pieces (diameter $\geq 0.05 \mathrm{~m}$; length $\geq 0.5 \mathrm{~m}$ ) and those that were still alive but entirely uprooted. We excluded snags, following Young et al. (2006), defined as pieces leaning or suspended over the stream at an angle greater than $30^{\circ}$. In wood jams ( $>2$ pieces), we measured pieces that were accessible and whose functions were not influenced by the functions of other pieces. Three larger wood jams ( $>10$ and $<50$ pieces) were present in 3 reaches. Only downed SW extending within bankfull boundaries were included in the tallies.

We measured channel widths every $10 \mathrm{~m}$ ( $\sim 51$ widths per reach) using a laser meter (precision: $1 \mathrm{~mm}$ ) and a target. Exposed rooted vegetation was observed to retain $\mathrm{SW}$ in our stream reaches. Consequently, we measured only the unobstructed channel width, i.e. the portion of the channel width available to transport wood unimpeded, every $10 \mathrm{~m}$ for each study reach. We defined channel obstructing vegetation as rooted stems at least $3 \mathrm{~cm}$ diameter within the bankfull channel, and measured the widest unobstructed channel width in regards to potential wood transport. When no obstructing vegetation was present, we recorded the distance across the stream between bankfull channel margins. At the reach scale, mean channel widths ranged from 1.34 to $12.75 \mathrm{~m}$ and bed slopes ranged from 0.02 to $7.80 \%$.

We recorded the following SW characteristics:

(i) Burned status of the SW piece was assessed following Jones and Daniels (2008), using three classes (unburned: no char; moderately: charred bark but outermost ring present in at least one part of the circumference; heavily: charred bark and sapwood resulting in significant ring loss);

(ii) Source tree (maritime pine, eucalyptus, cork oak, or "riparian species") was identified by assessing morphological characteristics of the wood piece;

(iii) Length in meters was determined to the nearest $0.2 \mathrm{~m}$ for the segments of the pieces that were $>1 \mathrm{~cm}$ in diameter. We measured length using a meter tape for pieces $>6 \mathrm{~m}$ long, and estimated length for pieces $<6 \mathrm{~m}$ (verified for the first 20 pieces per reach);

(iv) Diameter was determined to the nearest $0.5 \mathrm{~cm}$ by a single measurement taken from a point considered the mean diameter by visual assessment. For pieces $>15 \mathrm{~cm}$ diameter, we measured using a meter tape; for pieces $<15 \mathrm{~cm}$, we estimated (verified for the first 20 pieces per reach);

(v) Decay of the SW piece was assessed using the four classes proposed by Jones and Daniels (2008) (evaluating bark, branches, and overall structural integrity);

(vi) Class of the SW piece form (straight; bent; strongly bent);

(vii) Presence of rootwads (yes/no);

(viii) Presence of branches (yes/no).

We recorded the following metrics, quantifying SW relationships with the stream channel:

(i) Horizontal orientation of each SW piece, starting upstream, parallel to the thalweg direction, and rotating clockwise $\left(0^{\circ}, 30^{\circ}\right.$, $60^{\circ}, 90^{\circ}, 120^{\circ}, 150^{\circ}$ );

(ii) Position of the SW on the stream (bridge: log spans channel, touching both banks and resting on the floodplain; loose: resting entirely on the streambed; ramp: resting on one bank only). Due to sample size, 54 wood pieces forming collapsed bridges were reclassified as ramps; (iii) Anchoring (number of ends or sides attached or buried in either the bank or the stream: $0-4$ );

(iv) Wood length/channel width ratio per wood piece was derived from its length divided by the nearest channel width;

(v) Percent distance of the wood piece along the stream. The center of each piece was geo-referenced with a GPS unit (whenever possible, with a $0.3-1 \mathrm{~m}$ precision by post-processing). The GPS reading was taken for 30-60 s and the average recorded then converted to a distance along the stream thalweg and then to percentage $(0 \%=$ stream source; $100 \%=$ stream mouth $)$.

The function of each piece of SW was assessed with respect to its role in deflecting flow (e.g. creating pools or riffles, forming steps), retaining bedload or sediment (sediment wedge $>2 \mathrm{~cm}$ deep and $>40 \mathrm{~cm}$ wide), armoring banks (e.g. protect bank from erosion, maintaining bank stability), creating debris jams (braced other wood or serving as a key piece in wood jams), retaining organic matter (twigs, leaves, fine organic matter; observable volume $>\sim 10^{-3} \mathrm{~m}^{3}$ ), or serving as a substrate to aquatic vegetation, periphyton, and/or epixylic biofilms (submersed wood with a conspicuous biofilm layer) or to conspicuous ovipositions (e.g. of amphibians). This variable was ultimately reduced to simple binary criteria: with/without function.

\subsection{Data analysis}

\subsubsection{Critical predictors to the stream wood function}

Relationships between the presence of observable functions of stream wood (function) and explanatory variables was explored using Generalized Additive Models (GAM; Wood, 2006; Zuur et al., 2009), thereby accounting for potential non-linearities in function responses. Because function was binary (wood piece with or without function), we used binomial GAM with a logit link. A matrix of Spearman's correlations for initial explanatory variables revealed that burned status was significantly correlated with decay $(r=0.404, p<0.001)$ and was excluded from GAM analysis, since a frequency analysis revealed no (direct) association of burned status alone and function. Correlations between the remaining variables used in the model were all $<|0.30|$, indicating that there were no collinearity problems. Prior to statistical analysis, diameter was log-transformed to approach normality and to reduce the influence of a few large values. For the analysis, decay, presence of rootwads, presence of branches, and horizontal orientation were treated as factors. Since collected data were nested within 27 stream reaches, we compared GAM and Mixed-GAM (with stream reach as a random factor), and chose the first as it had the lowest value for Akaike Information Criterion $(\triangle \mathrm{AIC}=5258)$. All calculations were carried out using R (R Development Core Team, 2009). The mgcv package (Wood, 2006) was used to fit GAM, using penalized regression splines with the optimal amount of smoothing estimated by unbiased risk estimator (UBRE). We defined the basis dimension $(k=5)$ to allow some complexity in the functions, while avoiding over-fitting the data.

The modeling procedure involved the fitting of the full model, with the six SW characteristics and the five relationships with the stream channel defined above, followed by backward elimination of non-significant $(p>0.05)$ variables (Zuur et al., 2009). Model fit was evaluated by the proportion of the null deviance explained.

\subsubsection{SW burned status and critical predictors to the stream wood function}

We used structural equation modeling (SEM; Arbuckle, 2010) to separately examine the linkages between significant factors in GAM plus SW burned status related to function. Additionally, SEM allowed us to highlight indirect effects not revealed by GAM. Using 
Table 1

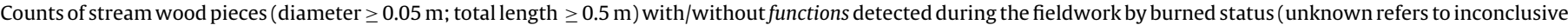
visual assessment of burned status). Values represent pieces intercepting the bankfull.

\begin{tabular}{|c|c|c|c|c|c|}
\hline \multirow[t]{2}{*}{ Stream wood function } & \multicolumn{4}{|c|}{ Number of stream wood pieces by burned status } & \multirow[t]{2}{*}{ Total } \\
\hline & Unburned & Moderately burned & Heavily burned & Unknown & \\
\hline Function not detected & 272 & 238 & 118 & 66 & 694 \\
\hline With functions detected & 303 & 214 & 168 & 104 & 789 \\
\hline Total & 575 & 452 & 286 & 170 & 1483 \\
\hline
\end{tabular}

the software IBM SPSS Amos ${ }^{\mathrm{TM}}$, a path diagram was constructed first based on theory using the exogenous variables for each wood piece. Error terms were added as needed, and regression weights were examined to iteratively add (based on modification indices) or remove (based on $p$-values) linkages from the model. Once a good model fit was achieved, based on both the minimum discrepancy (Browne, 1984) and the root mean square error of approximation, function was added as a categorical endogenous variable with linkages from all other variables. Bayesian estimation was then used on the retained paths to fit the model, and linkages to function were iteratively removed based on the posterior distributions of the regression weights. Linkages were removed if their $80 \%$ credible interval did not include zero (considered supportive of a model derived from maximum likelihood procedures). For the SEM analysis, SW position was reduced to simple binary criteria: bridge/non-bridge.

\section{Results}

\subsection{Critical predictors to the stream wood function}

Overall, $53.1 \%$ of the 1483 pieces of stream wood were deemed to have a function in our surveys, and $51.8 \%$ of the burned wood subset was functional (Table 1). Evaluation of the significance of variables resulted in the sequential dropping of branch presence, horizontal orientation, decay, form, and source tree. The resulting model is shown in Table 2 and Fig. 1. The significant SW characteristics were diameter and presence of rootwads. The probability of function increased on pieces of greater diameter and the same trend was found for pieces with rootwads.

Regarding SW relationship with the stream channel, the significant variables were anchoring, position, distance along the stream, and length/channel width ratio. Wood pieces with more anchoring sides in either the bank or the stream had a higher probability of having a function. Concerning position, wood resting entirely on the streambed (loose) had a higher probability of having an observable function, followed by pieces resting on one bank only (ramp), and finally, pieces spanning the channel, touching both banks and resting on the floodplain (bridges) had the lowest probability of performing a function. As for distance, pieces at both beginning and ending of streams tended to have a similar lower probability of function; this probability was higher in the second half of streams, reaching a peak at $\sim 3 / 4$ of the stream length. Finally, wood longer than $\sim 3$ times the channel width tended to have a decreasing relationship with probability of function.

\subsection{SW burned status and critical predictors to the SW function}

A variety of linkages were present among variables (Fig. 2), and the factors that affected function directly were the same as those identified by the GAM. In addition to the direct effects, several indirect effects (those connecting predictor variables) were identified where the variable's effect on function was mediated by another variable. We highlight that SW burned status indirectly affected function positively through an effect on diameter. Moreover, burned status had a negative effect on anchoring, which, in turn, affected function positively. All linkages retained in the model had coefficients with a $90 \%$ credible interval, except length ratio, for which we used our cutoff of $80 \%$. The final structural equation model had a posterior predictive $p=0.42$ - indicating a good fit (Lee, 2007) - and was advantageous in identifying both unique and synergistic contributions of function predictor variables.

\section{Discussion}

The success of management initiatives to offset the long-term effects of wildfire on stream ecosystems will depend on understanding which wood fallen from burned riparian trees will tend to be functional in the river system and which will not. This study determined that - as hypothesized - burned status had the potential to influence wood function indirectly. Specifically, burned wood affected diameter positively and degree of anchoring negatively, with both relating positively to the probability of function. Overall, functionality of stream wood in this study was influenced

Table 2

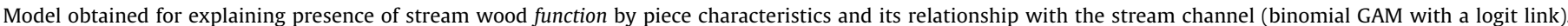

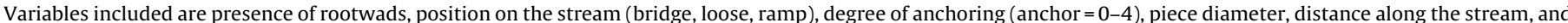
wood length/channel width ratio (lratio). Deviance explained $=19.7 \%$, UBRE score $=0.13$, edf $=$ effective degrees of freedom .

\begin{tabular}{|c|c|c|c|c|c|}
\hline Parametric coefficients & Estimate & & $z$-Value & & $\operatorname{Pr}(>|z|)$ \\
\hline (intercept) & $-3.21 \pm 0.35$ & & -9.23 & & $<0.0001$ \\
\hline factor(rootwads)yes & $0.58 \pm 0.26$ & & 2.27 & & 0.023 \\
\hline factor(position)loose & $2.75 \pm 0.25$ & & 11.01 & & $<0.0001$ \\
\hline factor(position)ramp & $1.77 \pm 0.21$ & & 8.47 & & $<0.0001$ \\
\hline factor(anchor) 1 & $0.85 \pm 0.30$ & & 2.84 & & 0.004 \\
\hline factor(anchor)2 & $1.83 \pm 0.30$ & & 6.15 & & $<0.0001$ \\
\hline factor(anchor)3 & $2.79 \pm 0.34$ & & 8.09 & & $<0.0001$ \\
\hline factor(anchor) 4 & $5.09 \pm 1.08$ & & 4.71 & & $<0.0001$ \\
\hline Smooth terms & edf & Chi.sq & & $p$-Value & \\
\hline$s$ (diameter) & 1.40 & 29.20 & & $<0.0001$ & \\
\hline$s$ (lratio) & 2.52 & 12.88 & & 0.006 & \\
\hline$s($ distance $)$ & 3.83 & 24.48 & & $<0.0001$ & \\
\hline
\end{tabular}


(a)

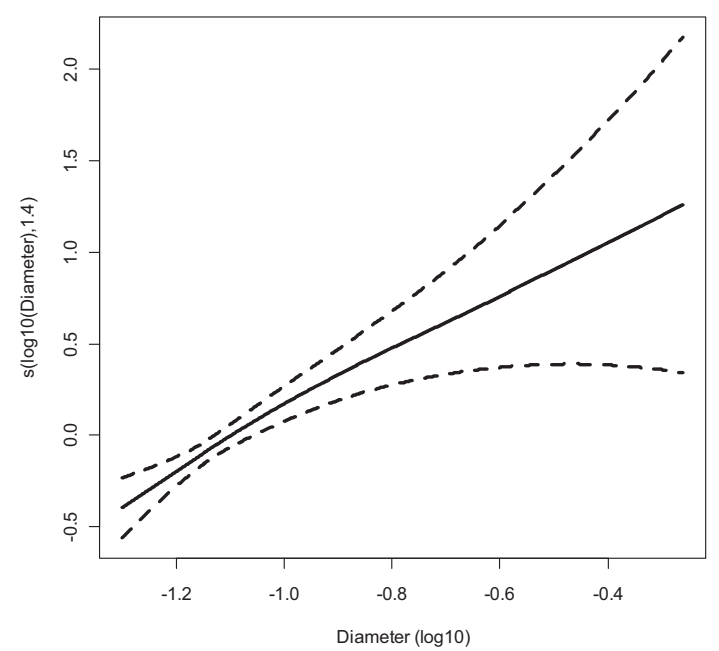

(c)

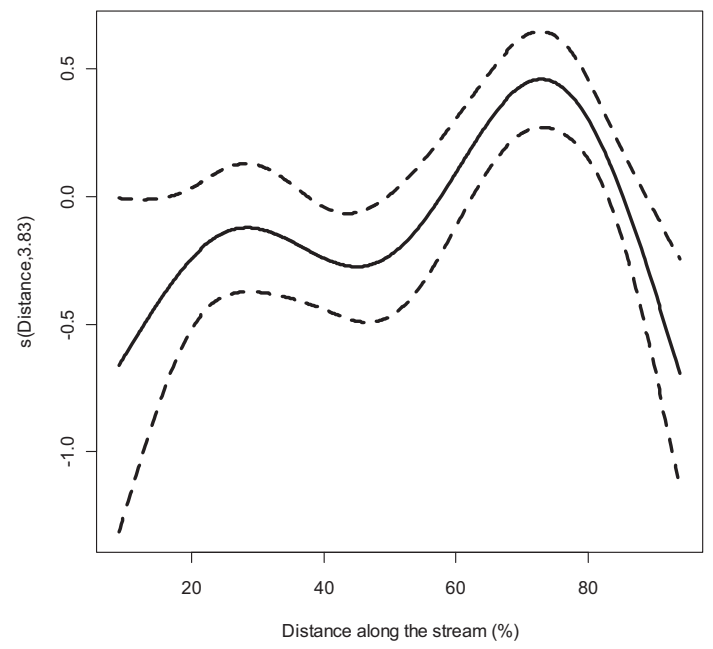

(e)

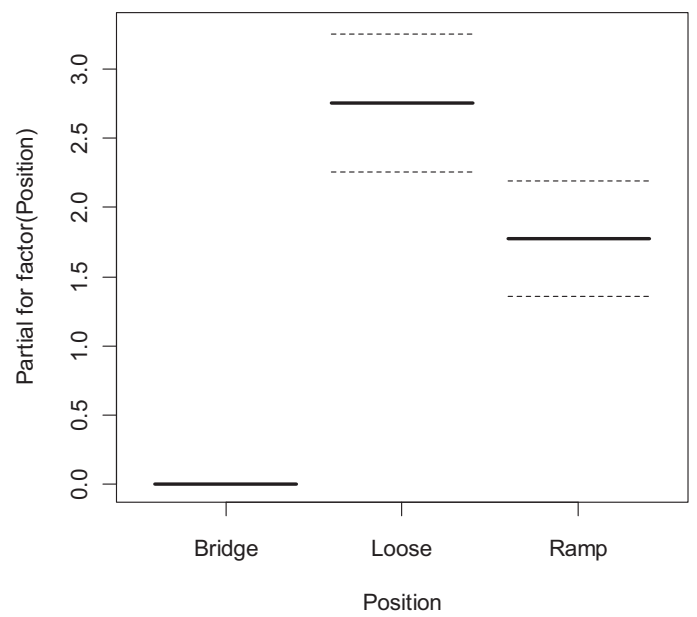

(b)

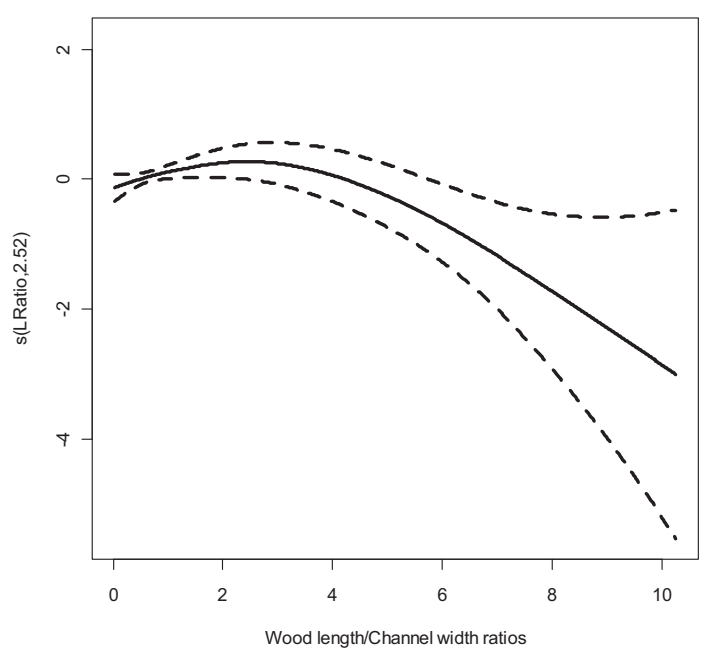

(d)

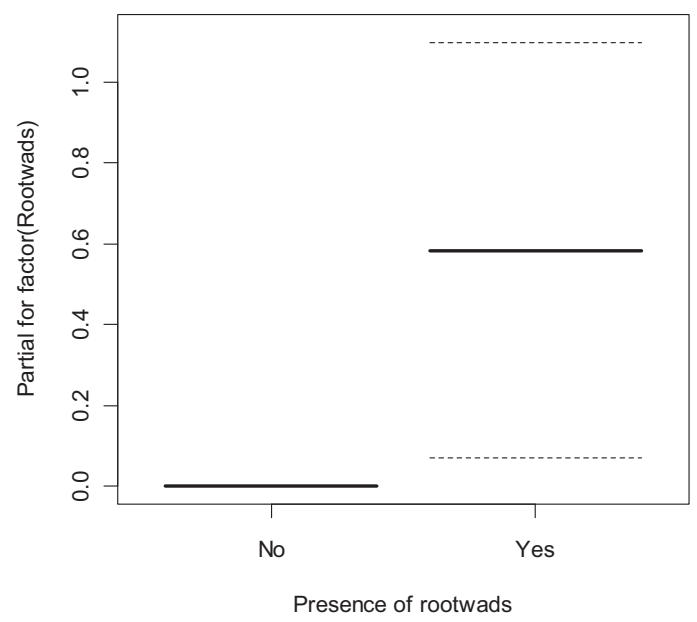

(f)

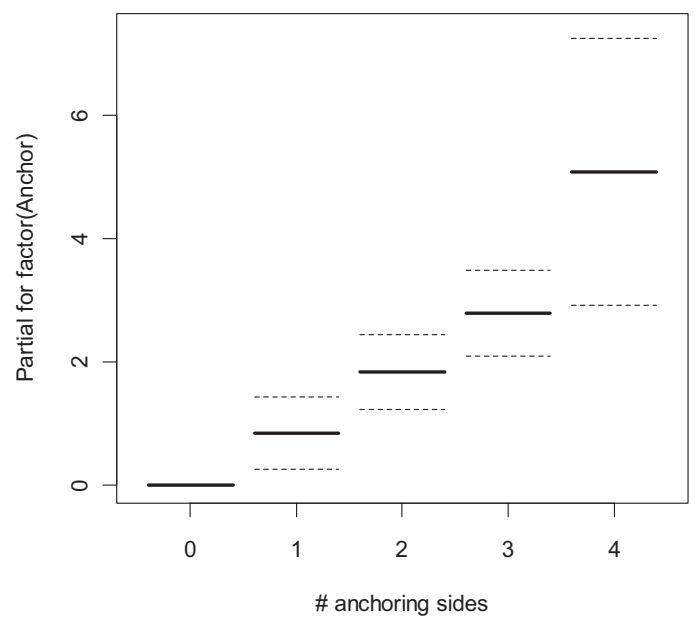

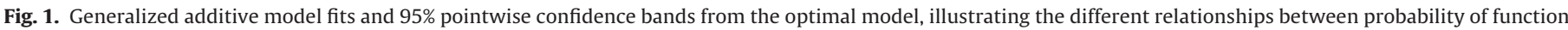

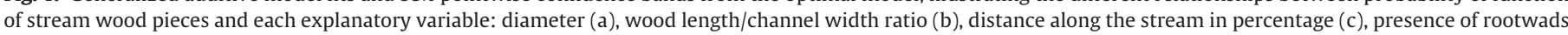
(d), position (e), and number of anchoring sides. Estimated degrees of freedom are given parenthetically in the $y$-axis label. 


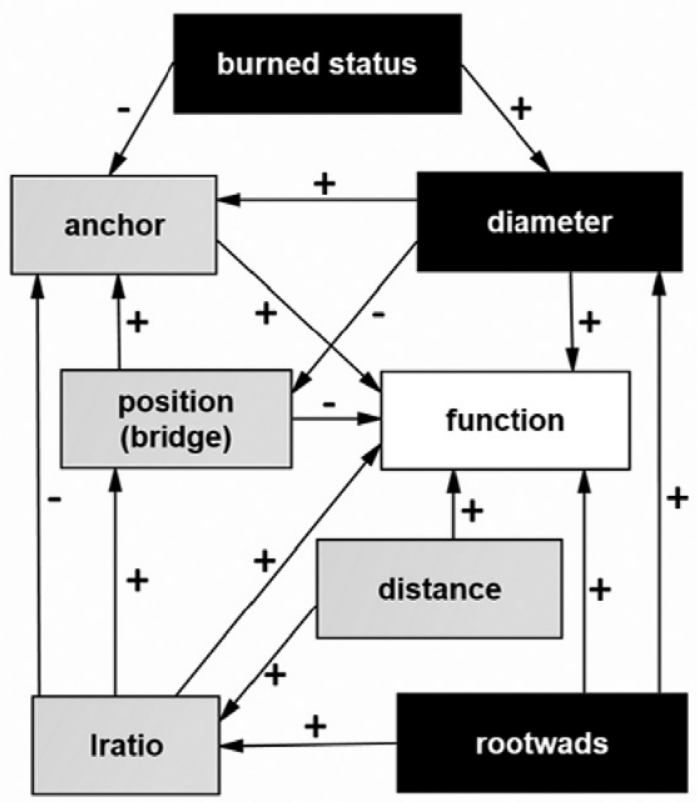

Fig. 2. Final structural equation model using Bayesian estimation to determine variables affecting function of instream wood pieces. Variables included are presence of rootwads, position on the stream (bridge/non bridge), degree of anchoring (anchor $=0-4$ ), piece diameter, distance along the stream, and wood length/channel width ratio (lratio). Gray: variables concerning wood relationship with the stream channel; black: SW characteristics. Arrows represent causal pathways from predictor to response variables. The sign associated with each arrow indicates whether the relationship is positive or negative for the unstandardized partial regression coefficient for that direct effect.

directly by four factors concerning the relationship with the stream channel and two factors concerning SW structural characteristics. By specifically quantifying functional wood and how critical predictors influenced the probability of function, our results allow more robust recommendations for improving riparian management techniques, particularly in fire-prone landscapes.

\subsection{What wood structure favors function within streams?}

Our study clearly demonstrated that stream wood functions were more likely for pieces thicker in diameter or with an attached rootwad. We suggest that these characteristics are relevant for a broad spectrum of SW functions, including their well-established role on the probability of pool formation and as primary controls on the stability of SW (Beechie and Sibley, 1997; Braudrick and Grant, 2000, 2001; Martin and Benda, 2001; Baillie et al., 2008; Magilligan et al., 2008). Piece diameter and the presence of rootwads (raising the center of mass of a piece) strongly influence the depth of flow required to entrain and transport logs (e.g. Bilby and Ward, 1989; Braudrick and Grant, 2000, 2001; Abbe et al., 2003), therefore likely influencing the prevalence of acquired functions. Owing to frequent forest disturbances by fire and management in this region, favoring the presence of young riparian trees with small diameters (Kreutzweiser et al., 2005), we found our results for SW diameter especially noteworthy. Although we were not able to measure bankfull depths, they greatly exceeded the average SW diameter $(9 \mathrm{~cm}$; P. Vaz, unpublished data), with consequences for transport and function. When considering eventual management initiatives, the inclusion of large wood, less common across these systems, acquires additional importance for stream function.
Our dataset has been used elsewhere to examine in detail stream wood physical structure in terms of burned status (Vaz et al., 2011). Among other structural differences, we concluded that, relative to unburned SW, burned wood was thicker in diameter and was more decayed. Here, we reiterate the trend for diameter and suggest that the effect of fire providing wood with greater diameter will also increase its probability for stream functions. On the other hand, among the potential SW critical factors, we found it striking that decay state had no significant effect on the probability of function given its importance in other systems. For example, Jones et al. (2011) found that less-decayed wood contributed less geomorphic functions in 21 streams in Alberta, Canada. A peculiarity of the SW across our 27 streams in central Portugal is that $90 \%$ was decayed (classes 3 and 4 adapted from Jones and Daniels, 2008) and that decay was positively associated to burned status (Vaz et al., 2011, 2013). Interestingly, if burning wood substantially increases the susceptibility of SW to decay, the functionality of wood amplified by greater diameters following fires may not persist.

\subsection{How and where is wood more functional within streams?}

This study contributed specifically to a better understanding on how and where wood should be located within a stream to be functional. Although prior works have recognized possible influences on functionality (Abbe et al., 2003; Montgomery et al., 2003; Cordova et al., 2007; Baillie et al., 2008; Magilligan et al., 2008; Jones et al., 2011), few specific guidelines exist as functionality has rarely been quantified. Also, we have shown that burned wood led to a reduction in anchoring, which corresponds to our expectations given that burnt pieces are straighter and less likely to have branches (Vaz et al., 2011). Another possibility is that less anchoring of burned wood reflected their recent arrival to the river system ( $<6$ years). In general, the degree of anchoring favoring functionality agrees with previous research stating that more stable wood has more influence on channel morphology (Jackson and Sturm, 2002; Andreoli et al., 2007; Comiti et al., 2008), since partial burial may be the single most important determinant of stability (Merten et al., 2010). Overall, the negative effect of fire on anchoring causes an indirect negative effect of fire on function, the opposite of the indirect effect mediated by diameter. On balance, the lack of a direct effect of fire on SW function is not surprising, given these opposing effects.

Concerning how SW rests within the channel, our finding that wood forming bridges tended to be less functional is in line with previous research from Jones and Daniels (2008). However, that study found the same trend for wood loose on the streambed, which is in marked contrast with our results where these pieces were the most functional. The discrepancy may be because Jones and Daniels (2008) focused on morphological functions, while we considered a wider range of functions. In fact, we estimate that $~ 50 \%$ of functional wood resting entirely on the streambed (loose) was performing biological/ecological functions only (P. Vaz, unpublished data). Moreover, loose wood in deep portions of the stream, where it is more likely to remain saturated, is more resistant to decay and thus prolonged the functionality in the system (Abbe et al., 2003).

Our analysis also expanded the current understanding of the role of the length ratio in determining function. The length ratio has been widely recognized as critical to transport processes (Haga et al., 2002; Merten et al., 2010, 2011) and - for pieces not oriented parallel to the flow - is related to channel blockage, which in turn is related to hydrodynamic drag (Hygelund and Manga, 2003). Pieces experiencing more drag, should they resist mobilization, are more likely to produce hydraulic functions such as flow deflection. However, a caveat exists regarding length ratio, as its relation to function tends to be greatly simplified, stating that longer pieces 
are invariably more stable and thus functional (Gurnell et al., 2002, Baillie et al., 2008). The possibility of diminishing function with greater lengths has only been recognized by Jones et al. (2011) who noted that - from a geomorphic perspective - functional wood averaged 2 times and non-functional wood averaged 6 times the channel width. Our GAM analysis showed that length ratio only increased the probability of function until a piece was 3 times the channel width, at which point further increases in length ratio led to decreased probability of function. Our SEM analysis gave a probable explanation. The model showed that length ratio, in fact, had a positive relationship with function, but only after the indirect effects of anchoring and bridging were accounted for. When considering a range of pieces including those much longer than the channel width, anchoring and bridging likely have synergistic contributions on function.

Finally, our results suggest a key zone along the river system located at about 3/4 of the stream's length where wood was most likely to be functional. In general, this demonstrated that functionality varies throughout the river network, but the reason for the peak in the second half of the streams is unclear and this trend opposes previous research focused on morphological functions (Baillie et al., 2008). However, our functions were not just morphological and, on the other hand, we did not perceive any particularity of the reaches representing the peak for function besides distance. At the end, extrapolating our results for distance must be considered cautiously. We speculate that more SW could be involved in various functional categories (not captured by morphological studies) with an increase on stream channel size (Chen et al., 2008), but only discriminating those functions and relating them to distance along the stream could shed light on our finding of more functional wood around 3/4 length of the stream. More work is still required to address how function changes with distance along the river.

\section{Management implications and conclusions}

Recognition of the value of wood to stream geomorphology, to stream biota, and to stream ecosystem function has lead to regular use of wood in stream management. Projects incorporating SW into restoration and riparian management are increasingly interested in functional predictors such as those assessed here (Abbe et al., 2003). Particularly, restoration projects are including the addition of potentially mobile wood that is expected to develop function more naturally with less reliance on bolts, cables, and rebar. To date these restorations rely largely on subjective decisions and lack a strong basis in research (Reich et al., 2003). Currently, there is a growing consensus that the use of wood in river restoration should be founded on emulating natural processes (Bisson et al., 2003), and the poor performance of some restoration projects is partially due to an insufficient understanding of what wood structure is optimal for the fluvial processes, and how and where wood can be placed to be more functional within streams.

Across fire-prone Euro-Mediterranean forestry systems, there are a wide range of post-fire human interventions in the riparian zone and associated streams. The type of forest management, from post-fire abandonment to active management near streams, has important consequences for SW function. In Portugal, to comply with national legislation, owners of land parcels in the beds and banks of inland waters are required to clean and clear the waterways. In contrast, the European water framework directive (WFD) requires "good conditions" that are "not far from natural conditions" for streams throughout Europe. Clearly, stream wood plays an important role to meet the intent of this policy, and authorities seek for good management practices following wildfires to meet WFD.
Our study provide useful information in developing guidelines for stream and riparian management operations. Interestingly, our suggestion that wood much longer than stream width is also less functional align well with security and navigability concerns, as this wood could also be the first to be removed after fire when decisions must be made which weigh safety versus ecosystem function. Nevertheless, we acknowledge that SW function is dynamic in space and time, and relatively long pieces may break or be transported downstream and become functional. Also, post-fire very long pieces may be less functional because they lack complexity. If complex, pieces long enough to create bridges may have branches protruding downward from the trunk and thus be functional (e.g. with the branches themselves trapping smaller pieces).

Our results challenge the well-established idea that the function of wood in streams is simply a matter of its stability, size, and decay state. As we demonstrated, SW further above the channel (e.g. bridging the channel) may be stable (well anchored) but may be unlikely functional. We also clarify the "size paradigm" by identifying a maximum-length ratio threshold above which SW is unlikely to be functional. Moreover, decay state was not a significant predictor of function, despite its relationship with burned status. Wood function was a result of synergistic contributions from several predictors, and although burned status itself was not a significant predictor, fire affected function indirectly by affecting both stability (via anchoring) and size (via diameter). Overall, our findings provide a way in which to refine the paradigm of wood functionality in streams with direct implications to stream management.

\section{Acknowledgements}

Pedro Vaz was funded by FCT - Portuguese Foundation for Science and Technology (SFRH/BD/45490/2008 and PEstOE/AGR/UI0520/2011). We thank the Dias family (Isidro, Elisa, Susana) for logistic support and accommodation, and João Jorge for help during fieldwork. Transportation was provided by the Department of Landscape, Environment and Planning, University of Évora (we especially thank Maria Rita Menezes, Maria Ilhéu, Vanda Prazeres, and Carlos Pinto Gomes). Tejo River Basin District Administration (Maria Helena Alves), and the National Water Authority (João Pádua and João Ferreira) helped in the acquisition of GIS data on the stream network.

\section{Appendix A. Supplementary data}

Supplementary data associated with this article can be found, in the online version, at http://dx.doi.org/10.1016/ j.ecoleng.2013.01.009. These data include Google map of the most important areas described in this article.

\section{References}

Abbe, T.B., Montgomery, D.R., 2003. Patterns and processes of wood debris accumulation in the Queets river basin, Washington. Geomorphology 51, 81-107.

Abbe, T.B., Brooks, A.P., Montgomery, D.R., 2003. Wood in river rehabilitation and management. In: Gregory, S.V., Boyer, K.L., Gurnell, A.M. (Eds.), The Ecology and Management of Wood in World Rivers. American Fisheries Society, Bethesda MD, pp. 367-389.

Andreoli, A., Comiti, F., Lenzi, M.A., 2007. Characteristics, distribution and geomorphic role of large woody debris in a mountain stream of the Chilean Andes. Earth Surf. Proc. Land. 32, 1675-1692.

Arbuckle, J.L., 2010. IBM SPSS Amos 19 User's Guide. Amos Development Corporation, Chicago, IL.

Baillie, B.R., Garrett, L.G., Evanson, A.W., 2008. Spatial distribution and influence of large woody debris in an old-growth forest river system. New Zeal. Forest Ecol. Manag. 256, 20-27.

Beechie, T.J., Sibley, T.H., 1997. Relationships between channel characteristics, woody debris, and fish habitat in northwestern Washington streams. T. Am Fish. Soc. 126, 217-229. 
Benda, L., Miller, D., Sias, J., Martin, D., Bilby, R., Veldhuisen, C., Dunne, T., 2003. Wood recruitment processes and wood budgeting. In: Gregory, S.V., Boyer, K.L., Gurnell, A.M. (Eds.), The Ecology and Management of Wood in World Rivers. American Fisheries Society, Bethesda, MD, pp. 49-73.

Bilby, R.E., Ward, J.W., 1989. Changes in characteristics and function of woody debris with increasing size of streams in western Washington. T. Am. Fish. Soc. 118, 368-378.

Bisson, P.A., Wondzell, S.M., Reeves, G.H., Gregory, S.V.,2003. Trends in using wood to restore aquatic habitats and fish communities in western north American rivers. In: Gregory, S.V., Boyer, K.L., Gurnell, A.M. (Eds.), The Ecology and Management of Wood in World Rivers. American Fisheries Society, Bethesda, pp. 391-406.

Bocchiola, D., Rulli, M.C., Rosso, R., 2006. Transport of large woody debris in the presence of obstacles. Geomorphology 76, 166-178.

Braudrick, C.A., Grant, G.E., 2000. When do logs move in rivers? Water Resour. Res. $36,571-583$.

Braudrick, C.A., Grant, G.E., 2001. Transport and deposition of large woody debris in streams: a flume experiment. Geomorphology 41, 263-283.

Browne, M.W., 1984. Asymptotically distribution-free methods for the analysis of covariance structures. Br. J. Math. Stat. Psychol. 37, 62-83.

Chen, X., Wei, X., Scherer, R., Hogan, D., 2008. Effects of large woody debris on surface structure and aquatic habitat in forested streams, southern interior British Columbia, Canada. River Res. Appl. 24, 862-875.

Comiti, F., Andreoli, A., Mao, L., Lenzi, M.A., 2008. Wood storage in three mountain streams of the southern Andes and its hydro-morphological effects. Earth Surf Proc. Land. 33, 244-262.

Cordova, J.M., Rosi-Marshall, E.J., Yamamuro, A.M., Lamberti, G.A., 2007. Quantity, controls and functions of large woody debris in Midwestern USA streams. River Res. Appl. 23, 21-33.

Gregory, S.V., Boyer, K.L., Gurnell, A.M., 2003. The Ecology And Management of Wood in World Rivers. American Fisheries Society, Bethesda, MD, USA.

Gurnell, A.M., Piégay, H., Swanson, F.J., Gregory, S.V., 2002. Large wood and fluvia processes. Freshwater Biol. 47, 601-619.

Haga, H., Kumagai, T.O., Otsuki, K., Ogawa, S., 2002. Transport and retention of coarse woody debris in mountain streams: an in situ field experiment of log transport and a field survey of coarse woody debris distribution. Water Resour. Res., 38

Hygelund, B., Manga, M., 2003. Field measurements of drag coefficients for mode large woody debris. Geomorphology 51, 175-185.

Jackson, C.R., Sturm, C.A., 2002. Woody debris and channel morphology in first- and second-order forested channels in Washington's coast ranges. Water Resour. Res. 38, 1117-1191.

Jones, T.A., Daniels, L.D., 2008. Dynamics of large woody debris in small streams disturbed by the 2001 dogrib fire in the Alberta foothills. Forest Ecol. Manag. 256, 1751-1759.

Jones, T.A., Daniels, L.D., Powell, S.R., 2011. Abundance and function of large woody debris in small, headwater streams in the rocky mountain foothills of Alberta, Canada. River Res. Appl. 27, 297-311.

Kreutzweiser, D.P., Good, K.P., Sutton, T.M., 2005. Large woody debris characteristics and contributions to pool formation in forest streams of the Boreal shield. Can. J. Forest Res. 35, 1213-1223.

Lee, S.Y., 2007. Structural Equation Modeling: A Bayesian Approach. Wiley, Chichester, UK.

Magilligan, F.J., Nislow, K.H., Fisher, G.B., Wright, J., Mackey, G., Laser, M., 2008. The geomorphic function and characteristics of large woody debris in low gradient rivers, coastsine, USA. Geomorphology 97, 467-482.
Manga, M., Kirchner, J.W., 2000. Stress partitioning in streams by large woody debris. Water Resour. Res. 36, 2373-2379.

Martin, D.J., Benda, L.E., 2001. Patterns of instream wood recruitment and transport at the watershed scale. T. Am. Fish. Soc. 130, 940-958.

Merten, E., Finlay, J., Johnson, L., Newman, R., Stefan, H., Vondracek, B., 2010. Factors influencing wood mobilization in streams. Water Resour. Res. 46, W10514.

Merten, E.C., Finlay, J., Johnson, L., Newman, R., Stefan, H., Vondracek, B., 2011. Environmental controls of wood entrapment in upper midwestern streams. Hydrol. Process. 25, 593-602.

Montgomery, D.R., Collins, B.D., Buffington, K.M., Abbe, T.B., 2003. Geomorphic effects of wood in rivers. In: Gregory, S., Boyer, K., Gurnell, A. (Eds.), The Ecology and Management of Wood in World Rivers. American Fisheries Society, Bethesda, MD, pp. 21-47.

Nakamura, F., Swanson, F.J., 2003. Dynamics of wood in rivers in the context of ecological disturbance. In: Gregory, S.V., Boyer, K.L., Gurnell, A.M. (Eds.), The Ecology and Management of Wood in World Rivers. American Fisheries Society, Bethesda, MD, pp. 279-297.

R Development Core Team, 2009. R: A Language and Environment for Statistical Computing. R Foundation for Statistical Computing. R Development Core Team, Vienna, Austria, ISBN 3-900051-07-0 http://www.r-project.org

Reich, M., Kershner, J.L., Wildman, R.C., 2003. Restoring streams with large wood: a synthesis. In: Gregory, S., Boyer, K., Gurnell, A. (Eds.), The Ecology and Management of Wood in World Rivers. American Fisheries Society, Bethesda, MD, pp. 355-366.

Rosenfeld, J.S., Huato, L., 2003. Relationship between Large Woody Debris Characteristics and Pool Formation in Small Coastal British Columbia Streams. N. Am. J. Fish. Manag. 23, 928-938.

Silva, J.S., Vaz, P., Moreira, F., Catry, F., Rego, F.C., 2011. Wildfires as a major driver of landscape dynamics in three fire-prone areas of Portugal. Landscape Urban Plan. 101, 349-358.

Strahler, A., 1957. Quantitative analysis of watershed geomorphology. Trans. Am. Geophys. Union 38, 913-920.

Thompson, D.M., 1995. The effects of large organic debris on sediment processes and stream morphology in Vermont. Geomorphology 11, 235-244.

Vaz, P.G., Warren, D.R., Pinto, P., Merten, E.C., Robinson, C., Rego, F.C., 2011. Tree type and forest management effects on the structure of stream wood following wildfires. Forest Ecol. Manag. 262, 561-570.

Vaz, P.G., Warren, D.R., Merten, E.C., Robinson, C., Pinto, P., Rego, F.C., 2013. Effects of forest type and stream size on volume and distribution of stream wood: legacies of wildfire in a Euro-Mediterranean context. Freshwater Science 32, $126-141$.

Wohl, E., Cenderelli, D.A., Dwire, K.A., Ryan-Burkett, S.E., Young, M.K., Fausch, K.D., 2010. Large in-stream wood studies: a call for common metrics. Earth Surf. Proc. Land. 35, 618-625.

Wood, S.N., 2006. Generalized Additive Models: An Introduction with R. Chapman and Hall/CRC, Boca Raton.

Young, M.K., Mace, E.A., Ziegler, E.T., Sutherland, E.K., 2006. Characterizing and contrasting instream and riparian coarse wood in western Montana basins. Forest Ecology and Management 226, 26-40.

Zelt, R.B. Wohl, E.E. 2004. Channel and woody debris characteristics in adjacent burned and unburned watersheds a decade after wildfire, park county, Wyoming. Geomorphology 57, 217-233.

Zuur, A.F., Ieno, E.N., Walker, N., Saveliev, A.A., Smith, G.M., 2009. Mixed Effects Models and Extensions in Ecology with R. Springer, New York. 